\title{
Towards a standardized processing of Net Ecosystem Exchange measured with eddy covariance technique: algorithms and uncertainty estimation
}

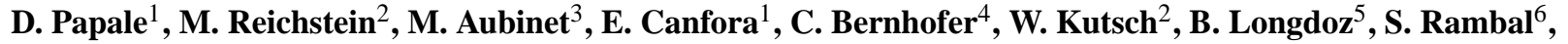 \\ R. Valentini ${ }^{1}$, T. Vesala ${ }^{7}$, and D. Yakir ${ }^{8}$ \\ ${ }^{1}$ Department of Forest Science and Environment, University of Tuscia, 01100 Viterbo, Italy \\ ${ }^{2}$ Max-Planck Institut fur Biogeochemie, P.O. Box 100164, 07701 Jena, Germany \\ ${ }^{3}$ Faculté des Sciences Agronomiques, Avenue de la Faculté d'Agronomie 8, 5030 Gembloux, Belgium \\ ${ }^{4}$ Dept. of Meteorology, Institute of Hydrology and-Meteorology, Technische Universitat Dresden, 01062 Dresden, Germany \\ ${ }^{5}$ Ecologie et Ecophysiologie Forestières, Centre de Nancy, 54280 Champenoux, France \\ ${ }^{6}$ Dream CEFE-CNRS, 1919 route de Mende, 34293 Montpellier, France \\ ${ }^{7}$ Department of Physical Sciences, University of Helsinki, P.O. Box 64, FIN-00014, Finland \\ ${ }^{8}$ Dept. of Environmental Sciences and Energy Research, Weizmann Institute of Science, P.O. Box 26, 76100 Rehovot, Israel
}

Received: 7 June 2006 - Published in Biogeosciences Discuss.: 13 July 2006

Revised: 26 October 2006 - Accepted: 16 November 2006 - Published: 27 November 2006

\begin{abstract}
Eddy covariance technique to measure $\mathrm{CO}_{2}$, water and energy fluxes between biosphere and atmosphere is widely spread and used in various regional networks. Currently more than 250 eddy covariance sites are active around the world measuring carbon exchange at high temporal resolution for different biomes and climatic conditions. In this paper a new standardized set of corrections is introduced and the uncertainties associated with these corrections are assessed for eight different forest sites in Europe with a total of 12 yearly datasets. The uncertainties introduced on the two components GPP (Gross Primary Production) and TER (Terrestrial Ecosystem Respiration) are also discussed and a quantitative analysis presented. Through a factorial analysis we find that generally, uncertainties by different corrections are additive without interactions and that the heuristic $\mathrm{u}_{*}$-correction introduces the largest uncertainty. The results show that a standardized data processing is needed for an effective comparison across biomes and for underpinning interannual variability. The methodology presented in this paper has also been integrated in the European database of the eddy covariance measurements.
\end{abstract}

\footnotetext{
Correspondence to: D. Papale

(darpap@unitus.it)
}

\section{Introduction}

The eddy covariance technique provides unique measurements of $\mathrm{CO}_{2}$, water and energy fluxes between the biosphere and the atmosphere at the ecosystem scale. Currently, more than 250 eddy covariance towers are acquiring data around the world (Baldocchi et al., 2001), covering different climate conditions, land use and land cover changes, some of them running continuously for more than 10 years. The eddy covariance technique is based on high frequency (10$20 \mathrm{~Hz}$ ) measurements of wind speed and direction as well as $\mathrm{CO}_{2}$ and $\mathrm{H}_{2} \mathrm{O}$ concentrations at a point over the canopy using a three-axis sonic anemometer and a fast response infrared gas analyzer (Aubinet et al., 2000; Aubinet et al., 2003a). Assuming perfect turbulent mixing these measurements are typically integrated over periods of half an hour (Goulden et al., 1996) building the basis to calculate carbon and water balances from daily to annual time scales.

There are different sources of uncertainties in the NEE flux measurements that are sometimes difficult to assess. Random measurement errors in flux data, including errors due to measurement system and turbulence transport, have been assessed by Hollinger and Richardson (2005), comparing the measurements from two towers with the same flux source area ("footprint") and by Richardson et al. (2006), comparing pair of measurements made on two successive days from the same tower under equivalent environmental conditions.

Published by Copernicus GmbH on behalf of the European Geosciences Union. 
Varying footprints can be a source of errors and uncertainties that can affect the data quality, particularly if the ecosystem is inhomogeneous and patchy (Göckede et al., 2006). In addition, several errors due to instrumentation limits may appear (acquisition frequency, sensor separation, fluctuation attenuation in closed systems, etc...). Most of these problems can be solved by applying correction procedures accordingly. However, it was shown by different authors (Aubinet et al., 2000; Goulden et al., 1996; Gu et al., 2005), independently of the preceding problems, eddy flux measurements can underestimate the net ecosystem exchange during periods with low turbulence and thus limited air mixing. This underestimation acts as a selective systematic error: it only occurs during the night when there is a net emission of $\mathrm{CO}_{2}$ by the ecosystem. As a consequence, the ecosystem respiration is underestimated and the carbon sequestration overestimated (Moncrieff et al., 1996).

Massman and Lee (2002) listed the possible causes of the night-time flux error. There is now a large consensus to recognise that the most probable cause of error is the presence of small scale movements associated with drainage flows or land breezes that take place in low turbulence conditions and create a decoupling between the soil surface and the canopy top. In these conditions, advection becomes an important term in the flux balance and cannot be neglected anymore. It was recently suggested (Finnigan et al., 2006) that, contrary to what was thought before, advection probably affects most of the sites, including almost flat and homogeneous ones. Direct advection flux measurements are difficult to measure as they require several measurement towers at the same site. Attempts were made notably by Aubinet et al. (2003b), Feigenwinter et al. (2004), Staebler and Fitzjarrald (2004) and Marcolla et al. (2005). They found that advection fluxes were usually significant during calm nights. However, in most cases, the measurement uncertainty was too large to allow their precise estimation. In addition, such direct measurements require a too complicated set up to allow routine measurements at each site.

In practice, the night flux problem is by-passed by discarding the data corresponding to low mixed periods and replacing them by an assessment based either on the parameterisation of the night flux response to the climate or on look up tables (Falge et al., 2001; Papale and Valentini, 2003; Reichstein et al., 2005). The friction velocity is currently used as a criterion to discriminate low and well mixed periods. This approach is generally known as the " $\mathrm{u}_{*}$ correction".

Although being currently the best and most widely used method to circumvent the problem, the $\mathrm{u}_{*}$ correction is affected by several drawbacks and must be applied with care.

First, an implicit application of the correction could lead to even bigger errors: indeed, during calm night conditions, the $\mathrm{CO}_{2}$ can be either removed by advection or stored in the canopy air. In the first case, the application of a $u_{*}$ correction is fully justified. However, in the second case, the $\mathrm{CO}_{2}$ stored in the canopy air would be removed by the turbulence as soon as it restarts. It would be captured at this moment by the eddy covariance system. If a $\mathrm{u}_{*}$ correction had been applied during the storage period, this flux would thus have been counted twice. One way to avoid this problem is to first correct the data for storage and then apply the $\mathrm{u}_{*}$ selection. However, this requires reliable $\mathrm{CO}_{2}$ storage measurements which are not always available at all sites. The best way to compute storage flux is to deduce it from $\mathrm{CO}_{2}$ concentration profiles made in the canopy. However, at many sites, a discrete estimation based only on the concentration at the tower top is used. It is likely that, in tall forests sites, such estimation is insufficient as it does not take the large concentration increase in the lower air layers into account. It is therefore important to understand the potential errors introduced using the discrete approach instead of the profile system.

Another problem with the $\mathrm{u}_{*}$ correction is that it depends on the operator's subjectivity. Indeed, the $\mathrm{u}_{*}$ threshold used to discriminate well and poorly mixed data is generally chosen by visual inspection. Different alternative heuristic methods were proposed to automatically determine the appropriate $\mathrm{u}_{*}$ threshold value ( $\mathrm{Gu}$ et al., 2005; Reichstein et al., 2003; Reichstein et al., 2005).

Finally, the hypotheses underlying the $\mathrm{u}_{*}$ correction are still debatable: firstly it is based on the assumption that flux in calm conditions can be inferred from measurements made in windy conditions, which is not proven. Secondly, it supposes that measurements made during turbulent periods are free of errors which is questioned by recent experiment results (Cook et al., 2004; Lee et al., 2004; Wohlfahrt et al., 2005).

There is a high heterogeneity in terms of quality and methods used in data processing. Many improvements in the Eddy measurements treatments were presented and applied over the last 10 years, often detailed information about the data processing methods were not available and important variables like the $\mathrm{CO}_{2}$ storage under the canopy were not measured. For this reason it is very important to have a set of tools to process all the datasets available with a standardized method with the aim to improve their quality, particularly if the data are used for interannual analysis or site intercomparisons, and where raw data are not available and for this reason it is impossible to use others criteria recently proposed (Rebmann et al., 2005; Ruppert et al., 2006).

It is also crucial to assess the effect of these integral flux corrections on data and the errors and uncertainties introduced. The sequence of analyses presented in this paper is based solely on half-hourly flux data to find the cases affected by common problems like spikes or low turbulence. Methodological uncertainties introduced by the different quality control procedures (e.g. $\mathrm{u}_{*}$ threshold selection) are systematically assessed at daily to annual time scales. Moreover, we also want to scientifically document the data processing applied in the CarboeuropeIP Ecosystem database (http://gaia. agraria.unitus.it/database) that now comprises more than 100 sites and a total of more than 250 site-years. 
Table 1. Sites and years used and main characteristics. $M F=$ mixed forest, ENF=evergreen needle forest, EBF=evergreen broadleaves forest, $\mathrm{DBF}=$ deciduous broadleaves forest, $\mathrm{ECO}=$ Ecosystem type, MAT=Mean Annual Temperature $\left({ }^{\circ} \mathrm{C}\right)$, Prec=Annual precipitation $(\mathrm{mm})$, LAI=Leaf Area Index (maximum).

\begin{tabular}{lllllllllll}
\hline Code & Years & Name & Lat. & Long. & ECO & MAT & Prec & LAI & Topography & Reference \\
\hline BE01 & 2001 & Vielsalm & $50^{\circ} 18^{\prime} \mathrm{N}$ & $5^{\circ} 59^{\prime} \mathrm{E}$ & MF & 7.5 & 1000 & 5.1 & Slope 3\% & (Aubinet et al., 2001) \\
DE02 & 2001,2002 & Tharandt & $50^{\circ} 57^{\prime} \mathrm{N}$ & $13^{\circ} 34^{\prime} \mathrm{E}$ & $\mathrm{ENF}$ & 7.7 & 820 & 7.6 & Gently sloped & (Bernhofer et al., 2003) \\
DE03 & 2001,2002 & Hainich & $51^{\circ} 04^{\prime} \mathrm{N}$ & $10^{\circ} 27^{\prime} \mathrm{E}$ & $\mathrm{DBF}$ & 6.8 & 775 & 6.4 & Gently sloped & (Knohl et al., 2003) \\
FI01 & 2001,2002 & Hyytiälä & $61^{\circ} 50^{\prime} \mathrm{N}$ & $24^{\circ} 17^{\prime} \mathrm{E}$ & $\mathrm{ENF}$ & 3.8 & 709 & 6.7 & Flat & (Suni et al., 2003) \\
FR01 & 2001,2002 & Hesse & $48^{\circ} 40^{\prime} \mathrm{N}$ & $07^{\circ} 03^{\prime} \mathrm{E}$ & $\mathrm{DBF}$ & 9.9 & 975 & 7.65 & Slope 3\% & (Granier et al., 2000) \\
FR04 & 2002 & Puechabon & $43^{\circ} 44^{\prime} \mathrm{N}$ & $03^{\circ} 35^{\prime} \mathrm{E}$ & $\mathrm{EBF}$ & 13.5 & 872 & 2.9 & Flat & (Rambal et al., 2004) \\
IL01 & 2002 & Yatir & $31^{\circ} 20^{\prime} \mathrm{N}$ & $35^{\circ} 03^{\prime} \mathrm{E}$ & $\mathrm{ENF}$ & 18.2 & 280 & 2 & Undulated & (Grunzweig et al., 2003) \\
IT03 & 2002 & Roccarespampani & $42^{\circ} 24^{\prime} \mathrm{N}$ & $11^{\circ} 55^{\prime} \mathrm{E}$ & $\mathrm{DBF}$ & 15.2 & 876 & 1.4 & Flat/Gently sloped & (Tedeschi et al., 2006) \\
\hline
\end{tabular}

\section{Materials and methods}

\subsection{Sites and processing overview}

For the present analyses, 12 annual datasets of $\mathrm{CO}_{2}$ exchange have been used from eight European eddy covariance sites (Table 1). The data were first storage corrected, then a spike detection technique was applied and, after that, filtered for low turbulence conditions (low $\mathrm{u}_{*}$ ). After these checks the yearly datasets were gap filled and the two components Gross Primary Production (GPP) and Terrestrial Ecosystem Respiration (TER) were estimated.

The storage flux $\left(\mathrm{S}_{c}\right)$ is calculated as (Aubinet et al., 2001):

$S_{c}=\frac{P_{a}}{R \cdot T_{a}} \int_{0}^{h} \frac{\partial c(z)}{\partial t} d z$

where $\mathrm{P}_{a}$ is the atmospheric pressure, $T_{a}$ is the air temperature, $R$ is the molar gas constant, $c$ is the $\mathrm{CO}_{2}$ concentration measured along a vertical profile, $h$ is the profile height. In practice the derivatives are approximated by finite differences between two successive measurements and the integrals are approximated by weighted sums of the concentrations measured at the different profile levels (generally between 4 and 7 measurement points). There are however sites where the profile system is not present or where it was not available during the first years of activity (FR01, FR04, IL01, IT03 in this paper). For these sites the only way to assess the storage flux is using the discrete approach, where the $\mathrm{CO}_{2}$ concentration measured at the top of the tower is considered constant inside the canopy.

\subsection{The spike detection method}

Eddy covariance measurements are often affected by spikes, due to different reasons both bio-physical (changes in the footprint or fast changes in turbulence conditions) and instrumental (e.g. water drops on sonic anemometer or on open path IRGA). The spikes affecting the single instantaneous measurement (high frequency spikes) are removed before the half-hourly average flux is calculated. However, spikes could also occur in the time series of the half hourly flux values and an outlier detection technique was applied to find these occasional spikes in the half-hourly flux data. These spikes commonly do not affect directly the annual NEE but can affect the quality of the gapfilled datasets. The algorithm used to detect the spikes is based on the position of each half hourly value with respect to the values just before and after and it is applied to blocks of 13 days and separately for daytime and night-time data. These night-time and daytime periods have been extended adding one value form the other period at the borders, needed to calculate $d_{i}$ (see later); night-time data were selected according to a global radiation threshold of $20 \mathrm{Wm}^{-2}$, cross-checked against sunrise and sunset data derived from the local time and standard sungeometrical routines. The outlier detection was based on the double-differenced time series, using the median of absolute deviation about the median (MAD) that is a robust outlier estimator (Sachs, 1996).

For each $\mathrm{NEE}_{i}$ half hourly data the $d$ value is calculated as:

$d_{i}=\left(\mathrm{NEE}_{i}-\mathrm{NEE}_{i-1}\right)-\left(\mathrm{NEE}_{i+1}-\mathrm{NEE}_{i}\right)$

and the value is flagged as spike if:

$d_{i}<M d-\left(\frac{z \cdot \mathrm{MAD}}{0.6745}\right)$

or

$d_{i}>M d+\left(\frac{z \cdot \mathrm{MAD}}{0.6745}\right)$

where $M d$ is the median of the differences, MAD is defined as

$\operatorname{MAD}=\operatorname{median}\left(\left|d_{i}-M d\right|\right)$

and $z$ is a threshold value.

Different $z$ values were used to assess the effect on the data and the sensibility of the method. In particular in this study we used three $z$ values: 4 , that is conventionally used and to be more conservative, 5.5 and 7 . 


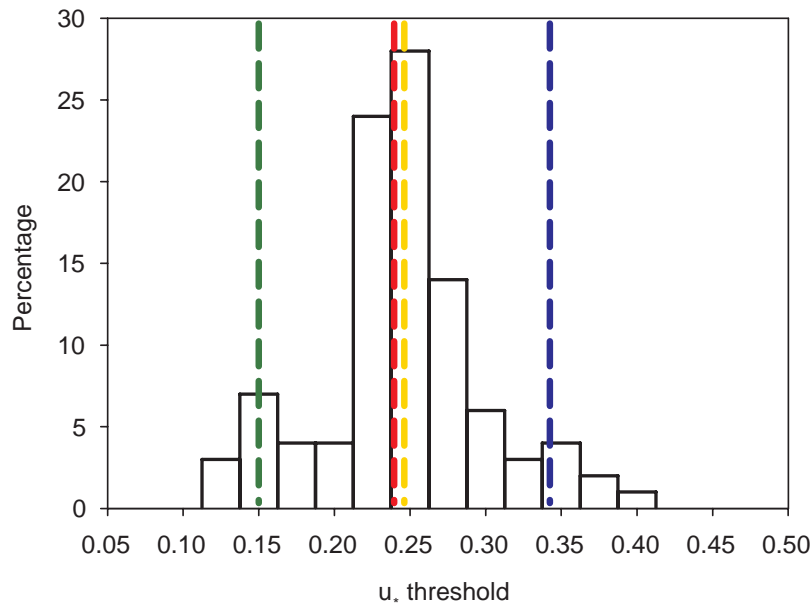

Fig. 1. Example of the variability in the $\mathrm{u}_{*}$ threshold found with the bootstrapping. Lines indicate mean (yellow), median (red), 5\% (green) and 95\% (blue) values. BE01_01, storage with discrete approach, spikes threshold $z=5.5$.

\subsection{The $\mathrm{u}_{*}$ threshold selection and uncertainty}

The $\mathrm{u}_{*}$-threshold was specifically derived for each site using a $99 \%$ threshold criterion on night-time data as described by (Reichstein et al., 2005). For the determination of the $u_{*}$ threshold, the data set is split into six temperature classes of equal sample size (according to quantiles) and for each temperature class, the set is split into 20 equally sized $\mathrm{u}_{*}$ classes. The threshold is defined as the $\mathrm{u}_{*}$-class where the average night-time flux reaches more than $99 \%$ of the average flux at the higher $\mathrm{u}_{*}$-classes. The threshold is only accepted if for the temperature class, temperature and $\mathrm{u}_{*}$ are not or only weakly correlated $(|\mathrm{r}|<0.4)$ The final threshold is defined as the median of the thresholds of the (up to) six temperature classes. This procedure is applied to the subsets of four 3-month periods (January-March, April-June, JulySeptember and October-December) to account for seasonal variation of vegetation structure.

The $\mathrm{u}_{*}$-threshold is reported for each period, but the whole data set is filtered according to the highest threshold found (conservative approach). In cases where no $\mathrm{u}_{*}$-threshold could be found in any of the 3-month periods with this approach, it is set to the $90 \%$ percentile of the data (i.e. a minimum $10 \%$ of the data are retained). A minimum threshold is set to $0.1 \mathrm{~ms}^{-1}$ for forest canopies and $0.01 \mathrm{~ms}^{-1}$ for short vegetation sites that commonly have lower $\mathrm{u}_{*}$ values (Falge et al., 2001; Gu et al., 2005). To be more conservative, in addition to the data acquired when $\mathrm{u}_{*}$ was below the threshold, the first half hour measured with good turbulence conditions after a period with low turbulence is also removed.

This procedure is repeated 100 times within a bootstrapping technique to asses the uncertainty of the $u_{*}$ threshold detection, where the whole annual dataset is bootstrapped (Efron and Tibshirani, 1993). The bootstrapping was carried in the following way: in each bootstrapping step, the whole year was sampled on a half-hourly basis into a data set with 17520 data points, where each half-hour can be drawn several times. Theoretically this procedure could lead to the case that considerably less points from a particular season (or from particular meteorological situations) are drawn introducing additional uncertainty. However due to the large number of data points (17520 half-hourly values) this is very unlikely. For example the probability that less than 4000 points are drawn from summer is $1.14 \times 10^{-11}$. The advantage of the bootstrapping is that parameters can be estimated without assumptions about the normal distribution and using also small samples size The effect of missing data is also included since missing data points are sampled with the same probability. The 5\% and 95\% percentiles of the 100 bootstrapped threshold estimates are taken as confidence interval boundaries (Fig. 1).

\subsection{Gap filling and partitioning of carbon fluxes}

To compare the effect of the different checks and filters applied at different time resolution (from daily to annual), all the datasets had to be filled. We used as gap-filling technique the method described in Reichstein et al. (2005) that exploits both the co-variation of fluxes with meteorological variables and the temporal autocorrelation of fluxes. The potential effect of different gap-filling methods on annual NEE is out of the scope of this paper, but it is systematically addressed in an ongoing work by Moffat et al. (2006) ${ }^{1}$ and seems to be generally small for the methods investigated (Papale et al., 2006).

The partitioning between Gross Primary Production and Terrestrial Ecosystem Respiration has been done according to the method proposed in Reichstein et al. (2005).

\section{Results and discussion}

\subsection{Variability and uncertainty of $\mathrm{u}_{*}$ threshold values}

For the 12 annual datasets used in this analysis, the different $\mathrm{u}_{*}$ thresholds and the 5\% and 95\% percentiles obtained after storage correction and spike detection are in a range that varies between 0.1 and $0.7 \mathrm{~m} \mathrm{~s}^{-1}$, as reported in Fig. 2. Noteworthy, the $\mathrm{u}_{*}$ threshold can be different for different sites, from very low values and low uncertainty as in FR01 to high values and uncertainty as in DE03, but is generally between 0.15 and $0.25 \mathrm{~m} \mathrm{~s}^{-1}$. This variability could be related to the characteristic of the site like canopy structure that have an

\footnotetext{
${ }^{1}$ Moffat, A., Papale, D., Reichstein, M., et al.: Comprehensive comparison of gap filling techniques for net carbon fluxes, in preparation, 2006.
} 
effect on the capacity of the eddies to penetrate in the forest, and topography that is one of the factors responsible for advection. In FI01 the threshold changes quite strongly between one year and the other and this could be related to one thinning of the forest that has been done in winter 2002. To better understand this variability in the $\mathrm{u}_{*}$ threshold between sites more detailed analysis are necessary and important information could come from the advection studies and experiments that are currently carried out (Feigenwinter et al., 2006). In any case the bootstrapping method provides a non-parametric estimate of the $\mathrm{u}_{*}$-threshold uncertainty that is otherwise only hard to obtain. It is thus recommended to include an uncertainty estimate of the $\mathrm{u}_{*}$-threshold via a bootstrapping or similar sampling technique, which represents an important improvement over methods just providing a point estimate ( $\mathrm{Gu}$ et al., 2005).

The $\mathrm{u}_{*}$-threshold value and his uncertainty given by the difference between the 5 and 95 percentiles must however not be confounded with the uncertainty introduced in the flux data (e.g. annual sums) as will be shown later in the paper (Fig. 9 later in this paper).

This method for the $\mathrm{u}_{*}$-threshold selection has been applied in this study only to forest sites, however the use of the maximum value found in the four 3-month periods makes this method also appropriate for ecosystems where the vegetation structure change more rapidly like agricultural and managed grassland ecosystems. Figure 3 shows the effect of the different corrections and in particular $\mathrm{u}_{*}$ filtering to the fluxes. The plots are relative to BE01 with storage calculated using discrete approach and each of the 4 subplots is obtained using April to September night-time data in the same range of temperatures (indicated in the title of the subplot). The temperature ranges are automatically chosen in a way that the same number of data are used in each subplot. Also the $12 \mathrm{u}_{*}$ classes for each temperature class are automatically selected to have the same number of data in each classes. If $\mathbf{u}_{*}$ correction would not be needed NEE should be independent from $u_{*}$. The differences between NEE_gf and NEE in the $u_{*}$ classes above the threshold are due to the spike filtering but over all to the first measurement with high $\mathrm{u}_{*}$ after a period with low turbulence that are also removed as explained before in the text. It is possible to see that Fc decrease with low turbulence conditions but the storage flux doesn't compensate it while after the corrections the night time fluxes are, in average, more independent from $u_{*}$ as expected.

\subsection{Effect of storage and $\mathrm{u}_{*}$ correction}

According to the eddy covariance data processing method, the $\mathrm{CO}_{2}$ fluxes are corrected by storage fluxes and after that filtered by $\mathrm{u}_{*}$ to remove measurements acquired during low turbulence conditions. These two corrections have to be done in the order described above to avoid the double counting effect, i.e. that (turbulent+storage) fluxes are removed during night with low $\mathrm{u}_{*}$ (and so the potentially high storage flux ig-

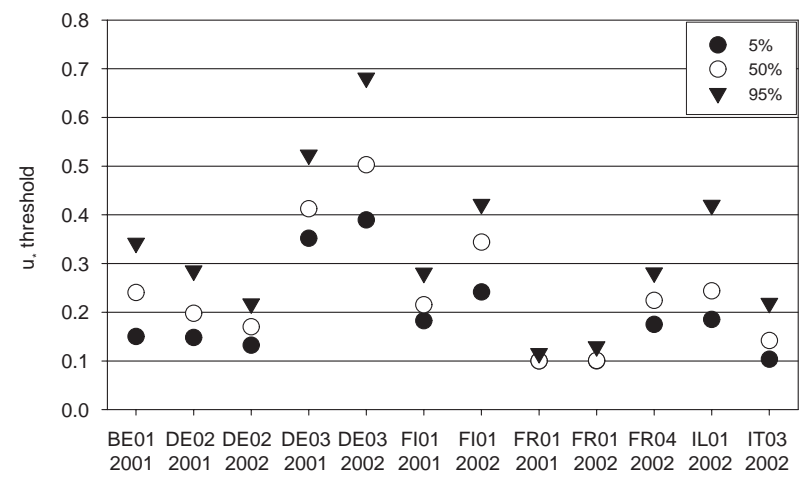

Fig. 2. Median and selected percentiles of the $\mathrm{u}_{*}$ threshold distribution determined by the bootstapping for the 12 yearly datasets for discrete approach storage calculation and spike threshold $z=5.5$.

nored) while during the following morning the depletion of the storage is accounted for (Aubinet et al., 2002). Figure 4 shows the annual NEE obtained for the different sites/years by using different treatments: the recommended one (first storage, then $\left.\mathrm{u}_{*}\right), \mathrm{u}_{*}$ correction only, storage correction only, and no corrections. The little differences between data without corrections and data only storage corrected, that theoretically should be exactly the same for the annual NEE, are due to the different number of gaps (e.g. if storage flux is missing, but not turbulent flux). It is possible to see that the differences between the four annual NEE presented for each site and year vary a lot from site to site. For example for FR01 the differences are in the order of $30-40 \mathrm{gC} \mathrm{m}^{-2} \mathrm{yr}^{-1}$ (between 5 and 10\%) while for IT03 the differences are very strong and the site changes from sink to source of carbon using the different thresholds. The effect of the $u_{*}$ filtering leads to reductions of the annual NEE as expected except for FR01 where the changes are in the opposite direction. This could be due to the small $u_{*}$-threshold value used for this site that have a limited impact on the annual NEE. Another interesting point is that the double counting problem (differences between right correction and only $\mathrm{u}_{*}$ ) is evident for most of the sites (BE01, DE02, FR04, IL01 and IT03) while for some sites it is not clear: in FI01 there is not a clear difference and this can be due to the small effect that the $u_{*}$ filtering have on the annual NEE (see later Fig. 8 and Fig. 9a), the same happens in FR01 where the trend changes from one year to the other and can be also related to the little impact of the $\mathrm{u}_{*}$ filtering as discussed before. In DE03 the trend is in the opposite direction as expected and could be related to the presence of strong horizontal advection where $\mathrm{u}_{*}$ filtering could be not enough to correct the data as discussed later in the paper and to the high number of daytime data removed by the filtering. 

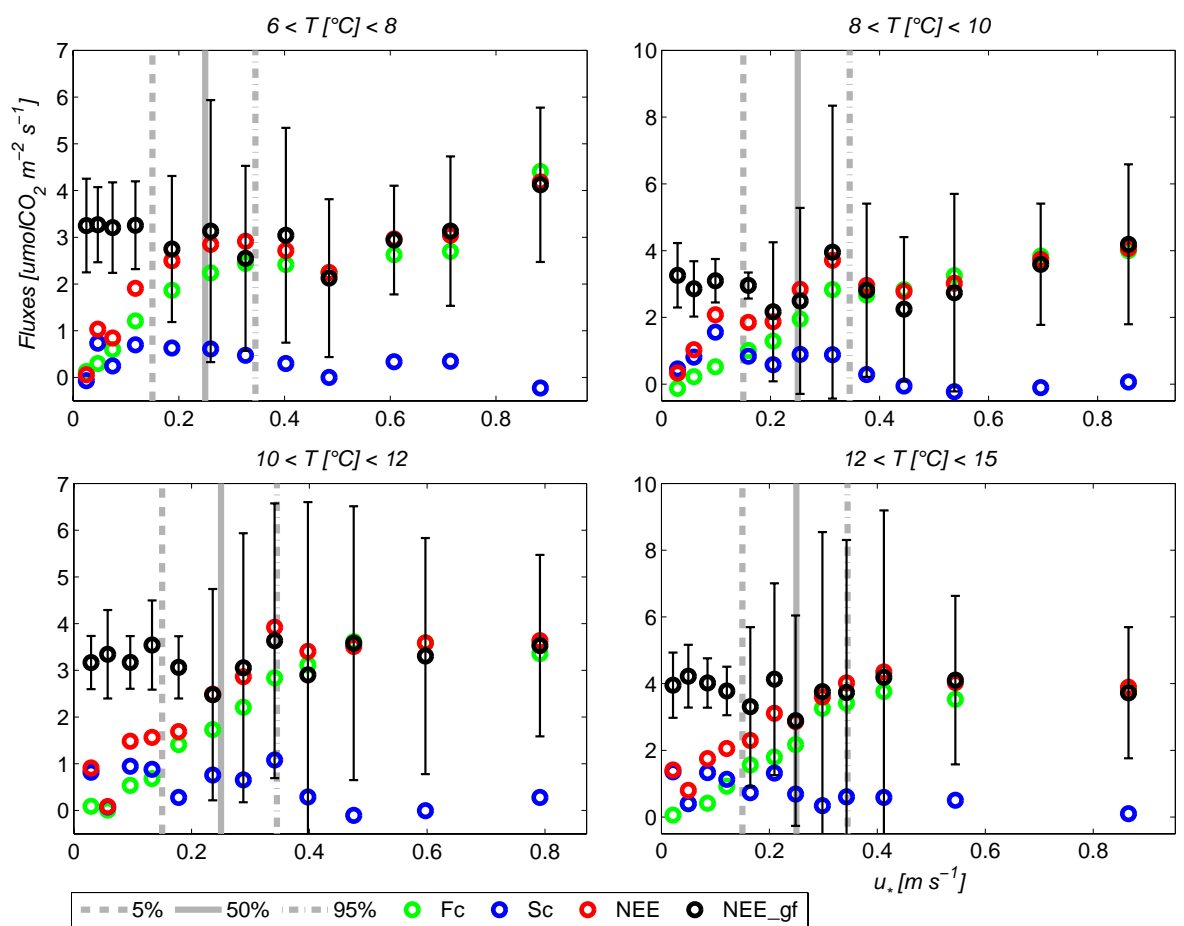

Fig. 3. Effect of the different corrections on the relation between $u_{*}$ and fluxes (BE01_01). Data used in these plots are from April to September, night time only. Each subplot is obtained using data acquired when air temperatures was similar so that the fluxes (only respiration) are expected to be independent from turbulence. The grey lines are the selected $\mathrm{u}^{*}$ threshold and the 5\% and $95 \%$ percentiles of the 100 bootstapped threshold estimates. NEE_gf is the NEE after all the filtering and gapfilling and the errors bars indicate the standard deviation of NEE in each $u_{*}$ class. The method used to create these plots is conceptually similar to the method use to find the $u_{*}$ threshold but it is based on 6 months period and different temperature classes.

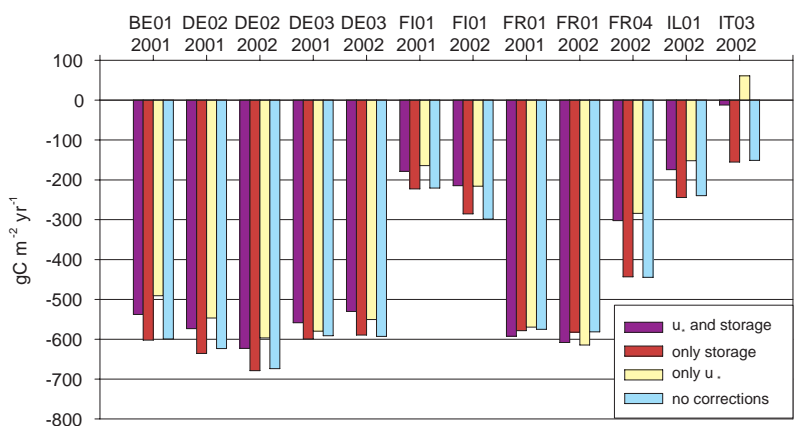

Fig. 4. Effect of storage and $\mathrm{u}_{*}$ corrections on annual NEE.

\subsection{Effect of the filtering techniques used}

The amount of data removed by the filtering algorithms was found variable as depicted in Table 2. The "Missing" column indicates the percentage of missing NEE values (not measured or affected by evident measurement problems like pump or gas analyzer broken); columns labelled as "Spike" show the percentages of additionally removed data, due to spike detection, using the three different thresholds. The three " $u_{*}$ " columns of Table 2 show the percentages of additionally removed data because acquired under stable conditions (with low $\mathrm{u}_{*}$ ) according with the three thresholds used. The last column lists the percentages of data removed using a "mean" configuration with spike threshold 5.5 and $50 \% \mathrm{u}_{*}$ threshold. It is evident that the largest percentages of data is removed by the $\mathrm{u}_{*}$ filtering, while the spike removal keeps largest part of the data untouched. Up to more than $50 \%$ of the night-time data are subject to this $\mathrm{u}_{*}$-based filter, while daytime data are less affected by turbulence problems, except for DE03 where in 2002 up to $50 \%$ of daytime data were filtered with the highest $\mathrm{u}_{*}$ threshold.

All the integral flux corrections and checks described above have an effect at different time scales, from the average daily trend to the annual sums. Figure 5 shows the monthly mean diurnal NEE trends for three site/years obtained using three different storage correction: with the storage term assessed using a $\mathrm{CO}_{2}$ concentration profile in the canopy (NEE_pr), assessed using the discrete approach using only the $\mathrm{CO}_{2}$ concentration measured on the top of the tower (NEE_sp) and without any storage correction $(\mathrm{Fc})$. Looking at the residuals, we note that without any storage correction a systematic error is introduced during both day and night time. The two errors go in the opposite direction 
Table 2. Percentage of half hourly data (storage corrected with the best method available at each site: BE01, DE02, DE03 and FI01 profile, FR01, FR04, IL01 and IT03 discrete approach) deleted in the different conditions. Missing: data not measured or deleted due to evident technical problems, Spike: additional data removed with the spike detection technique according with the different thresholds, $\mathrm{u}_{*}$ : additional data removed (after previous removal of spikes using threshold 5.5) due to low $\mathrm{u}_{*}$ conditions according with the three different thresholds, Total: the percentage of data removed summing missing data, spike with $z=5.5$ and $\mathrm{u}_{*} 50 \%$. The two numbers in italic are the percentages of night-time and daytime respectively for each site. All the percentages are relative to the year.

\begin{tabular}{|c|c|c|c|c|c|c|c|c|c|c|c|c|c|c|c|c|}
\hline Site_year & \multicolumn{2}{|c|}{ Missing } & \multicolumn{2}{|c|}{ Spike 4} & \multicolumn{2}{|c|}{ Spike 5.5} & \multicolumn{2}{|c|}{ Spike 7} & \multicolumn{2}{|c|}{$\mathrm{u}_{*} 5 \%$} & \multicolumn{2}{|c|}{$\mathrm{u}_{*} 50 \%$} & \multicolumn{2}{|c|}{$\mathrm{u}_{*} 95 \%$} & \multicolumn{2}{|c|}{ Total } \\
\hline \multirow{2}{*}{ BE01_01 } & \multirow{2}{*}{7.48} & 7.03 & \multirow{2}{*}{1.06} & 1.11 & \multirow{2}{*}{0.46} & 0.38 & \multirow{2}{*}{0.19} & 0.13 & \multirow{2}{*}{13.09} & 20.03 & \multirow{2}{*}{20.21} & 29.82 & \multirow{2}{*}{28.04} & 38.92 & \multirow{2}{*}{28.14} & 37.23 \\
\hline & & 7.92 & & 1.02 & & 0.54 & & 0.26 & & 6.15 & & 10.61 & & 17.17 & & 19.06 \\
\hline \multirow{2}{*}{ DE02_01 } & \multirow{2}{*}{9.82} & 8.61 & \multirow{2}{*}{1.89} & 2.28 & \multirow{2}{*}{1.02} & 1.36 & \multirow{2}{*}{0.46} & 0.68 & \multirow{2}{*}{13.35} & 21.87 & \multirow{2}{*}{17.45} & 28.15 & \multirow{2}{*}{28.15} & 42.18 & \multirow{2}{*}{28.29} & 38.12 \\
\hline & & 11.04 & & 1.50 & & 0.67 & & 0.23 & & 4.83 & & 6.76 & & 14.12 & & 18.47 \\
\hline \multirow{2}{*}{ DE02_02 } & \multirow{2}{*}{16.64} & 14.21 & & 2.31 & & 1.40 & & 0.64 & & 18.74 & & 24.52 & & 31.36 & & 40.14 \\
\hline & & 19.08 & 1.76 & 1.21 & 0.95 & 0.49 & 0.41 & 0.18 & 11.63 & 4.51 & 15.66 & 6.79 & 21.17 & 10.98 & 25 & 26.36 \\
\hline & & 17.80 & & 1.44 & & 0.64 & & 0.30 & & 25.83 & & 38.93 & & 47.01 & & 57.36 \\
\hline DE03_01 & 15.55 & 13.30 & 1.30 & 1.16 & 0.58 & 0.53 & 0.24 & 0.18 & 20.03 & 14.24 & 31.29 & 23.65 & 39.36 & 31.71 & 47.42 & 37.48 \\
\hline & & 18.58 & & 1.05 & & 0.62 & & 0.29 & 53 & 35.42 & & 47.35 & & 61.70 & & 66.55 \\
\hline _02 & 15.67 & 12.76 & 1.20 & 1.35 & 0.64 & 0.66 & 0.30 & 0.32 & .53 & 21.63 & 40.11 & 34.19 & 0.31 & 50.91 & 88 & 47.61 \\
\hline & & 19.38 & & 1.58 & & 0.76 & & 0.38 & & 21.15 & & 28.92 & & 37.52 & & 49.06 \\
\hline F101_01 & 14.25 & 9.12 & 1.27 & 0.97 & 0.59 & 0.41 & 0.29 & 0.21 & 15.64 & 10.14 & 21.68 & 14.45 & 29.12 & 20.71 & 0.52 & 23.98 \\
\hline & & 21.76 & & 1.40 & & 0.62 & & 0.23 & & 28.53 & & 37.63 & & 45.22 & & 60.00 \\
\hline F101_02 & 15.59 & 9.42 & 1.27 & 1.13 & 0.51 & 0.41 & 0.19 & 0.15 & 22.00 & 15.47 & 30.01 & 22.40 & 37.47 & 29.71 & 0.11 & 32.23 \\
\hline & & 8.94 & & 3.08 & & 2.04 & & 1.12 & & 23.29 & & 23.29 & & 26.75 & & 34.27 \\
\hline FRO1_01 & 1.63 & 6.31 & 2.84 & 2.60 & 1.87 & 1.70 & 1.13 & 1.14 & 5.26 & 7.23 & 15.26 & 7.23 & 1.92 & 9.09 & 4.75 & 15.24 \\
\hline FR01 02 & 841 & 9.24 & 263 & 3.46 & 160 & 1.91 & 087 & 1.04 & 1650 & 24.08 & 1660 & 24.19 & 2009 & 28.55 & 661 & 35.33 \\
\hline FRU1_02 & 8.41 & 7.58 & 2.63 & 1.80 & 1.60 & 1.29 & 0.81 & 0.70 & 10.50 & 8.92 & 16.60 & 9.02 & 20.09 & 11.62 & 20.61 & 17.89 \\
\hline & & 9.92 & & 2.18 & & 1.00 & & 0.43 & & 46.77 & & 52.67 & & 60.31 & & 63.60 \\
\hline FR04_02 & 9.51 & 9.10 & 1.88 & 1.59 & 0.86 & 0.71 & 0.41 & 0.38 & 31.60 & 16.44 & 37.45 & 22.24 & 46.28 & 32.25 & 47.82 & 32.04 \\
\hline & & 17.32 & & 1.87 & & 1.12 & & 0.63 & & 38.66 & & 46.70 & & 55.37 & & 65.14 \\
\hline 1L01_02 & 18.20 & 19.09 & $1.6 /$ & 1.47 & 0.92 & 0.72 & 0.48 & 0.33 & 23.58 & 8.49 & 29.49 & 12.28 & 36.89 & 18.42 & 48.61 & 32.09 \\
\hline IT03 02 & 606 & 6.54 & & 2.71 & & 1.82 & & 0.96 & & 34.20 & & 45.37 & & 62.44 & & 53.72 \\
\hline 1903_02 & 6.96 & 7.39 & 2.40 & 2.09 & 1.61 & 1.40 & 0.86 & 0.75 & 20.15 & 6.11 & 27.56 & 9.75 & 41.84 & 21.24 & 6.13 & 18.54 \\
\hline
\end{tabular}

with underestimation of night-time respiration and overestimation of daytime carbon uptake. It is also clear that the effect of the storage correction is different in the three sites, with minor effect for FI01 (Fig. 5c) that could be due to the more open canopy structure in particular in 2002 due to the thinning, but also related to the overall flux magnitude that is less compared to the others two sites. Analyzing the differences between the two storage correction options it appears that the differences are lower with respect to the comparison between storage and no storage correction at all and also the pattern is different and less systematic but still present (e.g. BE01 June and July, DE02 April and May, FI01 May and August). This problem is quite common in the old datasets where often the profile systems were not available. To better assess the storage flux in these datasets would be interesting to explore the possibility to retrieve a "storage correction factor" through a relation between the storage measured with the profile system and a series of variables like $\mathrm{CO}_{2}$ concentration at top of the tower, wind speed and direction, atmospheric pressure, temperature, etc. using methods able to find also complex relations between variables like Artificial Neural Networks (Papale and Valentini, 2003).

Figure 6 shows the effect of the different thresholds $z$ in the spike removing algorithm. The average daily trend has been calculated after filtering the data according with the $3 z$ values of 4, 5.5 and 7 and also without performing the spike detection at all. It is important to remark that the presence of spikes is related to different aspects and in particular to the site characteristics but also to the data screening operated by the PI. It is possible to see that the spike removing affects the mean diurnal cycles less than the storage correction. In addition, there is not a clear trend also if it seems that the major part of spikes for DE03 has been detected as "respiration" spikes and that there is a relation between the flux and the spike filtering magnitudes.

The analysis of the average daily trends does not give a clear quantitative information about the effect on the daily to annual budget. We characterise the intrinsic uncertainties of the correction methods by the difference between the maximum flux and minimum flux obtained depending on the method for each day, week or month. These uncertainties are presented in Fig. 7 as box-plots, where for example the median range of the different methods for daily fluxes across all the sites was $0.4 \mathrm{gC} \mathrm{m}^{-2} \mathrm{day}^{-1}$, considered as the median uncertainty of the corrections applied. As expected, the uncertainty is bigger in the daily sums compared to 8-daily and monthly aggregations. The $\mathrm{u}_{*}$ threshold selection is the most important source of uncertainty while storage, and in particular spike detection, have a smaller effect on the sums.

To understand the integral flux correction effects on annual 

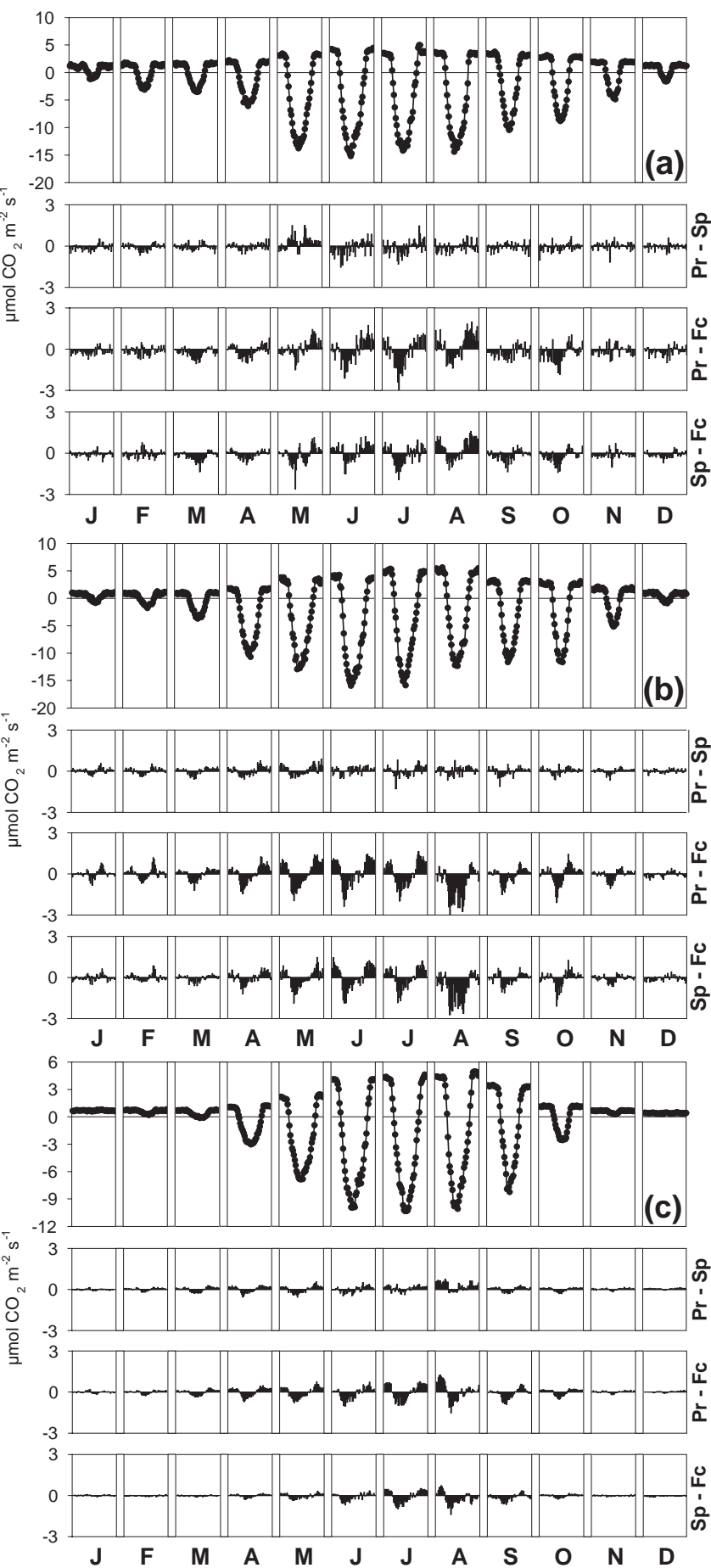

Fig. 5. Effect of different storage measurement methods on monthly mean diurnal NEE trends for three sites: BE01_01 (a), DE02_01 (b) and FI01_02 (c). In the upper panel diurnal cycle calculated from NEE_pr is shown; the other three panels the residuals respectively between the two storages ( $\mathrm{Pr}-\mathrm{Sp}$ ), between storage from profile and no storage correction $(\mathrm{Pr}-\mathrm{Fc})$ and between storage from discrete approach and no storage correction $(\mathrm{Sp}-\mathrm{Fc})$.

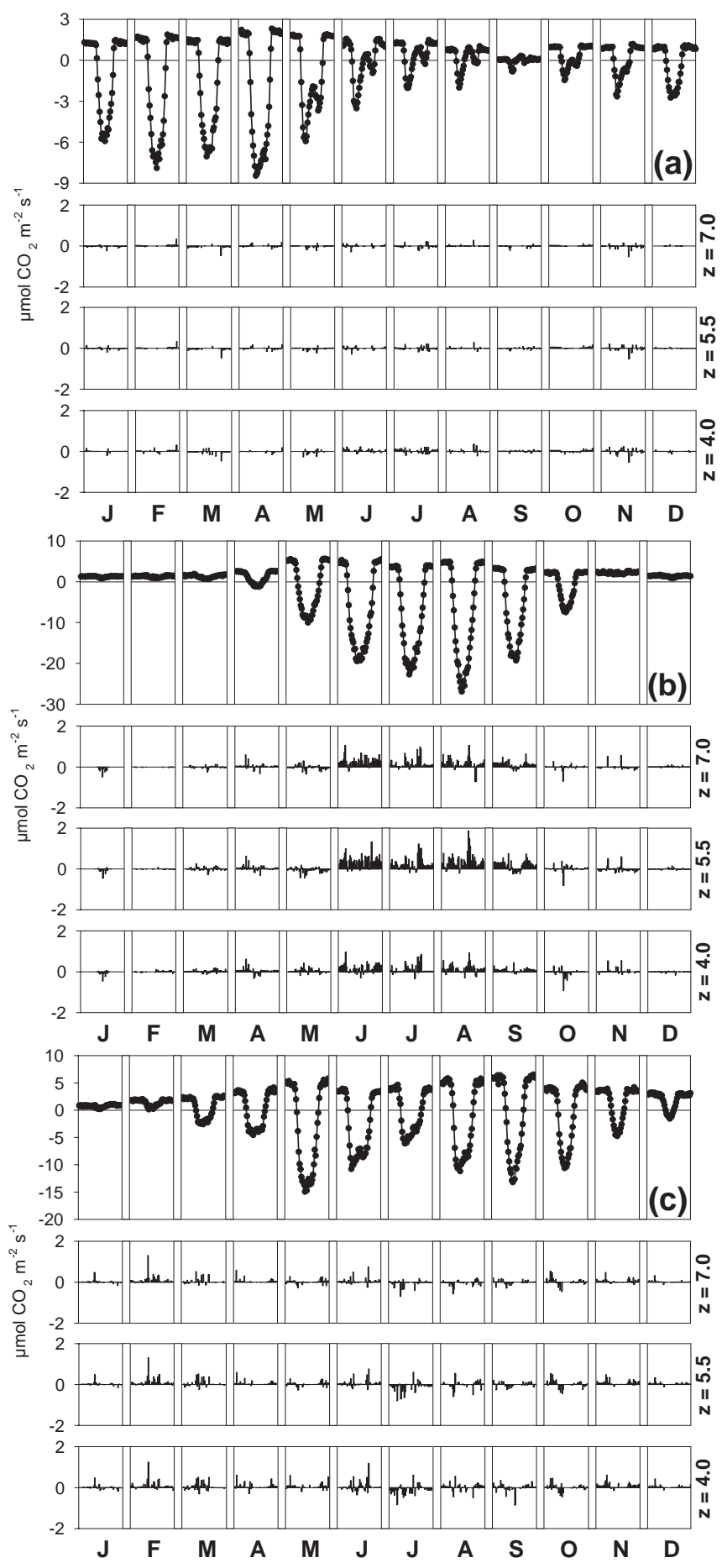

Fig. 6. Effect of different spike detection thresholds $z$ on monthly mean diurnal NEE trends for three sites: IL01_02 (a), DE03_02 (b) and IT03_02 (c). In the upper panel diurnal cycles calculated from data before spike detection is shown; the others three panels the residuals respectively between original and $z=7$, between original and $z=5.5$ and between original and $z=4$. 
NEE an ANOVA (Analysis of variance) has been performed using the annual NEE coming from the sites where the storage is measured also using the profile system. The summary of the results are shown in Fig. 8. The main source of uncertainty is confirmed to be $\mathrm{u}_{*}$ that is the main factor for three sites and in the fourth (FI01) is still important with $31 \%$. In addition it has to be noted that this analysis give information about the relative role of the different corrections in the total uncertainty definition but it is not directly related with the magnitude of the uncertainty. For DE03 $\mathrm{u}_{*}$ has a strong effect $(88 \%)$ and this is due to the differences in the three $\mathrm{u}_{*}$ thresholds selected that are the most variable compared with the other sites. Another important aspect is that the second order effects (interactions) are very low so that the three corrections seem to be independent from each other.

The NEE annual sums obtained with the different combinations of the corrections have been used as indicators of the methodological variability to analyze the effect of the different corrections on the annual balance (Fig. 9a). In the upper three panels the ranges of annual NEE due to each single correction are shown, while in the last plot the mean annual NEE and an error bar indicating minimum and maximum values obtained for each site/year. The mean annual NEE has been calculated using the best storage estimates, filtering the data by the $50 \% \mathrm{u}_{*}$ threshold and applying the spike detection with $z=5.5$. This $z$ value has been chosen instead of the conventionally used value $z=4$, because the latter is based on the assumption that the data are normally distributed while this is not always the case with the errors in flux data (Richardson et al., 2006).As seen before (Figs. 7, 8), the $u_{*}$ filtering has the strongest impact on the data, with generally an effect on the annual NEE of about $40 \mathrm{gC} \mathrm{m}^{-2} \mathrm{yr}^{-1}$. DE03 and IT03 are the sites with the highest $\mathrm{u}_{*}$ filtering impact on the annual NEE (about $70 \mathrm{gC} \mathrm{m}^{-2} \mathrm{yr}^{-1}$ ) while for other sites like FI01 it is very small (the same magnitude as the storage and spike filtering effects), also if the $u_{*}$ threshold found is one of the highest (cfr. Fig. 2). Looking to the annual NEE it is possible to see that the uncertainties are between 15 and $100 \mathrm{gC} \mathrm{m}^{-2} \mathrm{yr}^{-1}$ and in general between 10 and $20 \%$ except for IL01 where it is about 30\% and IT03 where the effect is strong enough to change the site from sink to source. It is also interesting to note that the uncertainties are of the same magnitude of the interannual variability in the four sites where we analyzed two years. This result stresses the importance of a standardized processing to avoid the introduction of artificial between-year and between-site variability that hampers comparative analysis.

The $\mathrm{u}_{*}$ filtering has been applied to daytime and nighttime data. However, there is still a debate on this, with part of the scientific community that applies the $\mathrm{u}_{*}$ filtering only to night-time data (Anthoni et al., 2004; Arain and RestrepoCoupe, 2005; Haszpra et al., 2005). Figure 9b shows the same plot as Fig. 9a, but in this case we filtered only the night-time data by $\mathrm{u}_{*}$. It is possible to see that the uncertainty due to $\mathrm{u}_{*}$ for DE03 dramatically decreases for both

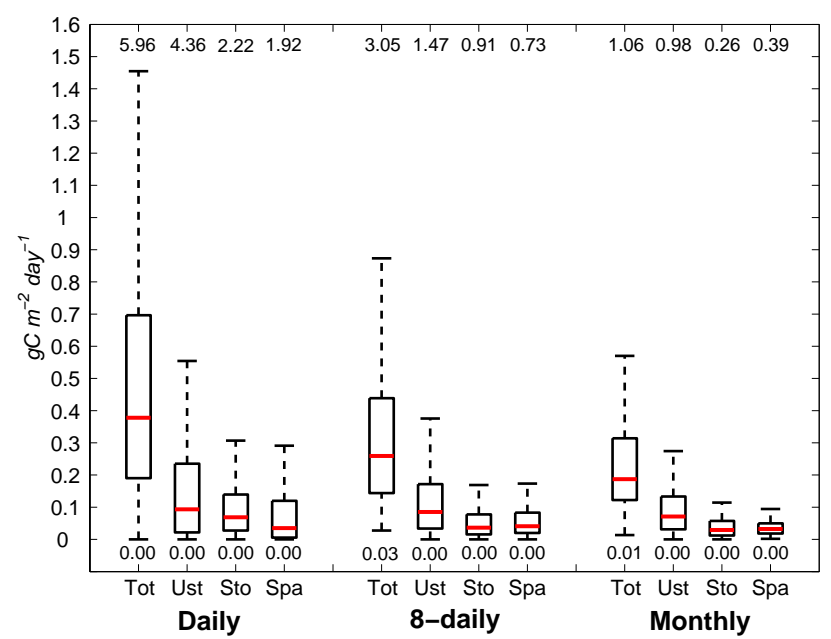

Fig. 7. Contribution of the different corrections (storage, $u_{*}$, spike) and total effect on daily, 8-daily and monthly NEE across all the sites. Boxplots indicate the range of values obtained applying respectively all the corrections (Tot), the three different $\mathrm{u}_{*}$ thresholds with the best storage possible and spike 5.5 (Ust), the two different storage calculation methods with $\mathrm{u}_{*} 50 \%$ and spike 5.5 (Sto) and the three different $\mathrm{z}$-values for the spike detection with the best storage possible and $u_{*} 50 \%$ (Spa). The red line indicates the median, the box the inter-quartile range and the dashed lines extending above and below the box show the extent of the rest of the sample (unless there are outliers). In this plot an outlier is a value that is more than 1.5 times the inter-quartile range away from the top or bottom of the box. The minimum and maximum outlier values are displayed as numbers at the top and bottom of the plot.

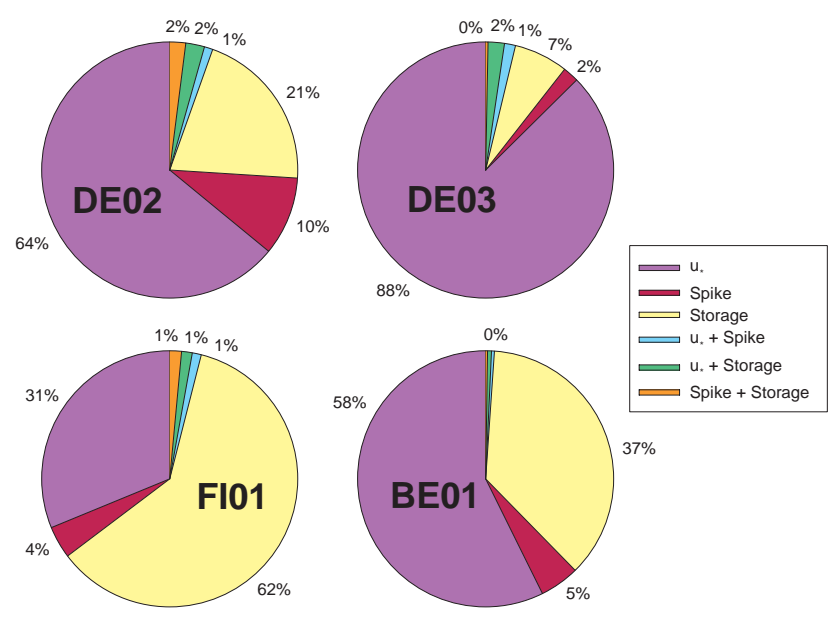

Fig. 8. Results of the ANOVA test on the four sites where both the methods to measure the storage flux have been available.

years and the same happens clearly to the annual budget uncertainty with a clear change also in the annual NEE. For the others sites there are no major differences, including IT03 where the $\mathrm{u}_{*}$ filtering effect is still large and also increased a 


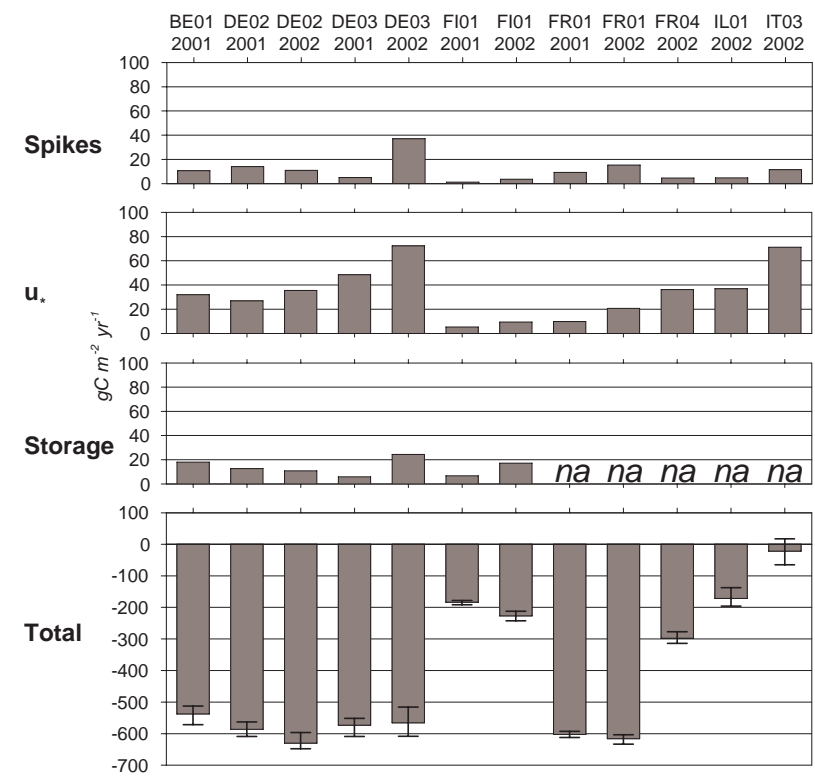

Fig. 9a. Effect of the three different corrections and total uncertainty introduced on the annual NEE for the different sites and years. $\mathrm{u}_{*}$ correction applied to daytime and night-time data. Ranges calculated taking into account 4 spikes detection level (4, 5.5, 7 and no spike filtering), $3 \mathrm{u}_{*}$ thresholds $(5 \%, 50 \%, 95 \%)$ and 2 storages calculation (single point and profile when available, na $=$ not available).

little. The reduction of uncertainty in DE03 can be explained by looking at the percentage of data removed by $\mathrm{u}_{*}$ filtering (Table 2): this is the site with the highest percentage of removed daytime data (up to more than $50 \%$ ) and with the highest ratio between daytime and night-time data removed (up to 0.82 for DE03 2002 with $u_{*} 95 \%$ ). DE03 is also the site where the $\mathrm{u}_{*}$ threshold is the highest and also most uncertain (Fig. 3). This could be indicative for strong advection occurring also at higher $\mathrm{u}_{*}$-values at this site, which would result in $\mathrm{u}_{*}$ filtering being not sufficient under those conditions (Kutsch et al., 2006 ${ }^{2}$ ). For IT03 we do not see a reduction of uncertainty if we remove only the night-time data with low $\mathrm{u}_{*}$. This is also partially related to the distribution of the filtered data between day and night because, unlike DE03, in this site the filtered data are mainly concentrated during night-time. Even though there is still debate on this we suggest, to be more conservative, to apply the $u_{*}$ filtering to both daytime and night-time also because the number of data removed during daytime is generally small.

Since the treatment of the NEE data can also have an effect on the partitioning into GPP and TER, we have also analysed the effect of the data treatment on these flux compo-

\footnotetext{
${ }^{2}$ Kutsch, W., Kolle, O., Rebmann, C., et al.: Process modelling and direct measurements of advection reveal uncertainties in flux measurements above a tall forest, Ecological Applications, submitted, 2006.
}

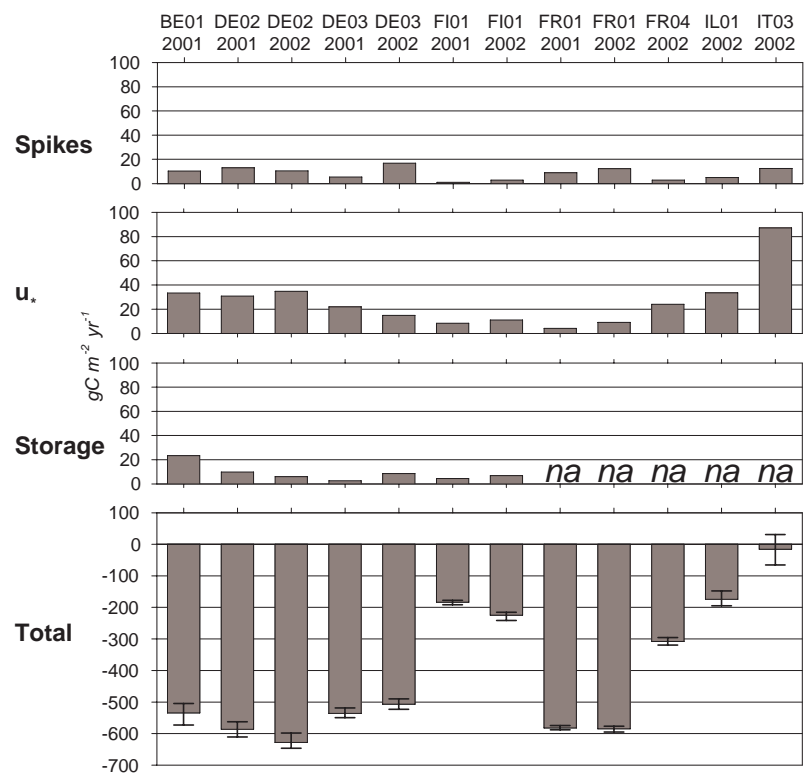

Fig. 9b. Effect of the three different corrections and total uncertainty introduced on the annual NEE for the different sites and years. $\mathrm{u}_{*}$ correction applied only to night-time data. Ranges calculated taking into account 4 spikes detection level $(4,5.5,7$ and no spike filtering), $3 \mathrm{u}_{*}$ thresholds $(5 \%, 50 \%, 95 \%)$ and 2 storages calculation (single point and profile when available).

nents (Figs. 9c, d). It seems that the absolute uncertainties introduced into the GPP by the corrections are about twice as high as for the net flux. This is expected since any error on the TER estimate from the night-time data will affect the GPP estimate in the same direction and hence be partially cancelled out when looking at NEE. Moreover, the methodological variability is higher for TER than for GPP, since dayand night-time TER estimates are affected by data treatment (night-time TER is extrapolated to the day, cf. Reichstein et al., 2005), while the GPP estimates are only during day-time (during night by definition zero). As for NEE the major uncertainty is introduced by the $\mathrm{u}_{*}$-filtering also for the flux components. Nevertheless at most sites the range of GPP and TER values obtained by different $\mathrm{u}_{*}$-thresholds is well below $100 \mathrm{gC} \mathrm{m}^{-2} \mathrm{yr}^{-1}$. Since GPP and TER are large fluxes, the relative methodological variability of those fluxes is below $10 \%$ in most cases.

\section{Conclusions}

In this paper a standardized set of integral flux corrections have been proposed with the aim to improve the quality of the NEE data from eddy covariance in particular for site intercomparisons. The methods have been applied and tested to 8 different forest sites but they can successfully be applied also to other ecosystem types with different structures and growing season lengths like cropland and grassland. 

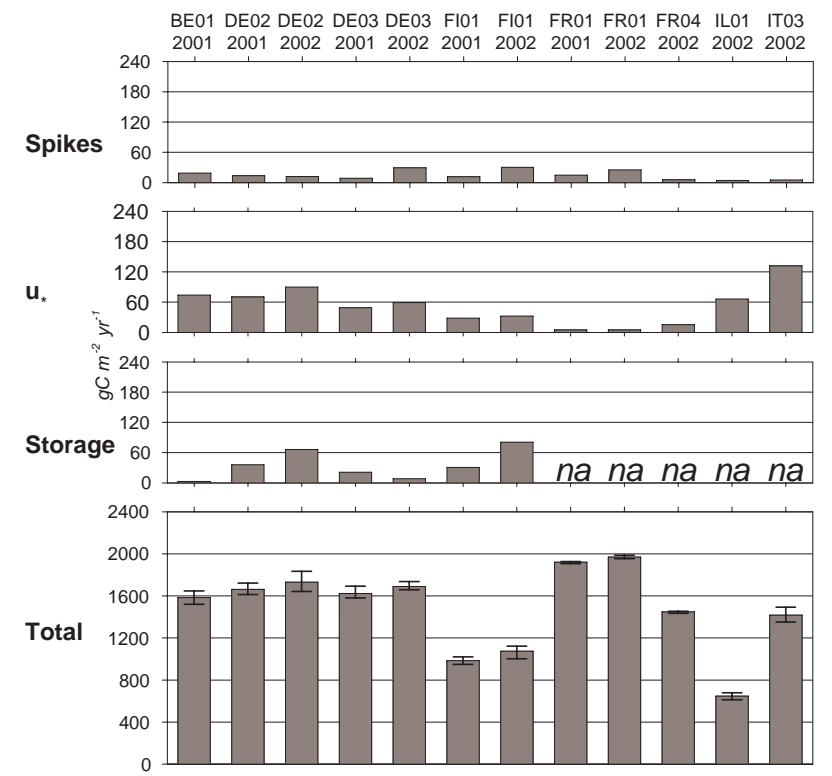

Fig. 9c. Effect of the three different corrections and total uncertainty introduced on the annual GPP for the different sites and years. $\mathrm{u}_{*}$ correction applied to daytime and night-time data. Ranges calculated taking into account 4 spikes detection level (4, 5.5, 7 and no spike filtering), $3 \mathrm{u}_{*}$ thresholds $(5 \%, 50 \%, 95 \%)$ and 2 storages calculation (single point and profile when available).

Intercomparisons of NEE data sets have been hampered so far by potential differences introduced by non harmonized data processing. We consider the present systematic characterization of the joint effects of $\mathrm{u}_{*}$-filtering, storage correction, and spike detection on net carbon fluxes and its components GPP and TER as an important step towards a more standardized processing and away from point estimates towards a better quantification of the likely range of integrals of eddy covariance $\mathrm{CO}_{2}$ flux data for a given site and year. We showed the importance of standardized processing that can strongly reduce the margin of uncertainties through a standardized processing also by avoiding inappropriate data treatment (e.g. neglect storage correction or $\mathrm{u}_{*}$-filtering), but it is also clear that heuristic methods like the $\mathrm{u}_{*}$-filtering contain an inherent uncertainty as found by the bootstrapping approach. Large uncertainties in the $\mathrm{u}_{*}$-thresholds and annual NEE affected by those at particular sites might also indicate general limits of an insufficiency of the heuristic $\mathrm{u}_{*}$-filtering method and standardized data processing at those sites, but it also suggests that this methodology may serve as tool to detect this problem, i.e. large uncertainties in the $\mathrm{u}_{*}$-threshold associated with large flux uncertainties introduced may be indicative of insufficiency of the $\mathrm{u}_{*}$-filtering approach. For a full uncertainty analysis of net $\mathrm{CO}_{2}$ fluxes and its components estimated by eddy covariance uncertainties introduced by non-captured advection, the gap-filling methods and the flux-partitioning have to be addressed separately. Nevertheless, from our study we conclude that uncertainties of annual NEE and its components GPP and TER introduced by the

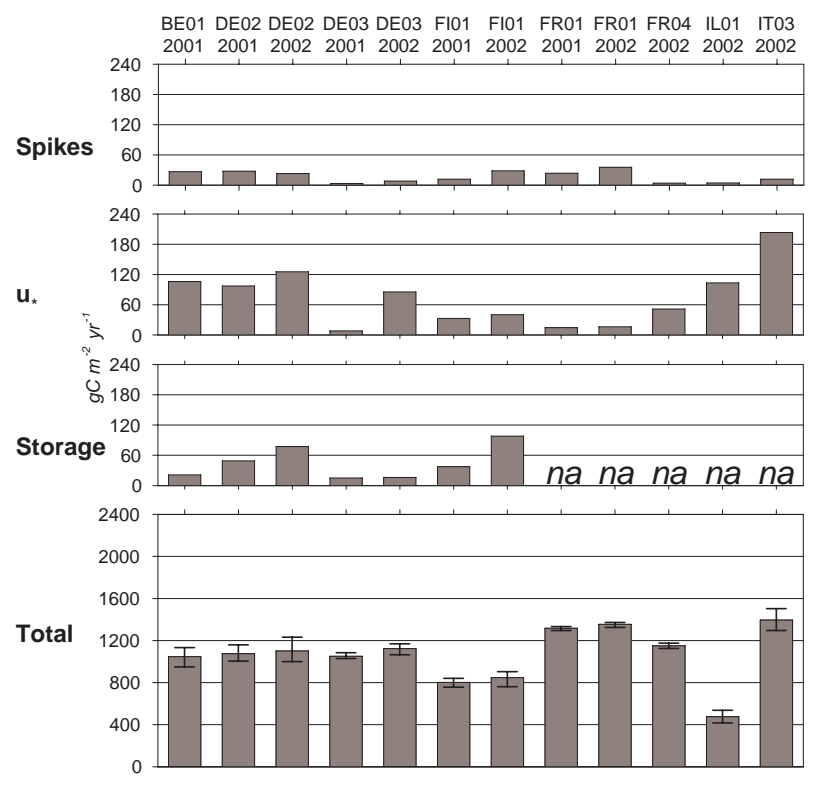

Fig. 9d. Effect of the three different corrections and total uncertainty introduced on the annual TER for the different sites and years. $\mathrm{u}_{*}$ correction applied to daytime and night-time data. Ranges calculated taking into account 4 spikes detection level $(4,5.5,7$ and no spike filtering), $3 \mathrm{u}_{*}$ thresholds $(5 \%, 50 \%, 95 \%)$ and 2 storages calculation (single point and profile when available).

corrections presented remain well below $100 \mathrm{gC} \mathrm{m}^{-2} \mathrm{yr}^{-1}$ and consequently, except for sites where others source of uncertainty dominate, that any spatial or temporal signals or trends that are larger than this number (e.g. continental gradients) can be detected by the eddy covariance method deployed as a coordinated network.

Acknowledgements. This work has been founded by EC project CarboeuropeIP (GOCE-CT2003-505572) of the European Community and the Italian-US joint program CarbiUS (Carbon Regional Balance Italy-USA). We wish to thank FLUXNET and therein D. Baldocchi for having largely created the conditions to build up the community of flux people and the integrated data analysis.

Edited by: A. Neftel

\section{References}

Anthoni, P., Freibauer, A., Kolle, O., and Schulze, E.-D.: Winter wheat carbon exchange in Thuringia, Germany, Agric. Forest Meteorol., 121, 55-67, 2004.

Arain, M. A. and Restrepo-Coupe, N.: Net ecosystem production in a temperate pine plantation in southeastern Canada, Agric. Forest Meteorol., 128, 223-241, 2005.

Aubinet, M., Grelle, A., Ibrom, A., Rannik, Ü., Moncrieff, J., Foken, T., Kowalski, A., Martin, P. H., Berbigier, P., Bernhofer, C., Clement, R., Elbers, J. A., Granier, A., Grunwald, T., Morgenstern, K., Pilegaard, K., Rebmann, C., Snijders, W., Valentini, R., 
and Vesala, T.: Estimates of the Annual Net Carbon and Water Exchange of Forest: The EUROFLUX Methodology, Advances in Ecological Research, 30, 114-173, 2000.

Aubinet, M., Chermanne, B., Vandenhaute, M., Longdoz, B., Yernaux, M., and Laitat, E.: Long term carbon dioxide exchange above a mixed forest in the Belgian Ardennes, Agric. Forest Meteorol., 108, 293-315, 2001.

Aubinet, M., Heinesch, B., and Longdoz, B.: Estimation of the carbon sequestration by a heterogeneous forest: night flux corrections, heterogeneity of the site and inter-annual variability, Global Change Biol., 8, 1053-1071, 2002.

Aubinet, M., Clement, R., Elbers, J. A., Foken, T., Grelle, A., Ibrom, A., Moncrieff, J., Pilegaard, K., Rannik, Ü., and Rebmann, C.: Methodology for Data Acquisition, Storage and Treatment, in: R. Valentini, Fluxes of Carbon, Water and Energy of European Forests, Springer-Verlag, Berlin, 2003a.

Aubinet, M., Heinesch, B., and Yernaux, M.: Horizontal and Vertical $\mathrm{CO}_{2}$ Advection In A Sloping Forest, Boundary-Layer Meteorol., 108, 397-417, 2003b.

Baldocchi, D., Falge, E., Gu, L., Olson, R., Hollinger, D., Running, S., Anthoni, P., Bernhofer, C., Davis, K., Evans, R., Fuentes, J., Goldstein, A., Katul, G., Law, B., Lee, X., Malhi, Y., Meyers, T., Munger, W., Oechel, W., Paw, K. T., Pilegaard, K., Schmid, H. P., Valentini, R., Verma, S., Vesala, T., Wilson, K., and Wofsy, S.: FLUXNET: A New Tool to Study the Temporal and Spatial Variability of Ecosystem-Scale Carbon Dioxide, Water Vapor, and Energy Flux Densities, Bull. Am. Meteorol. Soc., 82, 2415-2434, 2001.

Bernhofer, C., Aubinet, M., Clement, R., Grelle, A., Grünwald, T., Ibrom, A., Jarvis, P., Rebmann, C., Schulze, E.-D., and Tenhunen, J.: Spruce Forests (Norway and Sitka Spruce, Including Douglas Fir): Carbon and Water Fluxes and Balances, Ecological and Ecophysiological Determinants, in: R. Valentini, Fluxes of Carbon, Water and Energy of European Forests, Springer-Verlag, Berlin, 2003.

Cook, B. D., Davis, K. J., Wang, W., Desai, A., Berger, B. W., Teclaw, R. M., Martin, J. G., Bolstad, P. V., Bakwin, P. S., Yi, C., and Heilman, W.: Carbon exchange and venting anomalies in an upland deciduous forest in northern Wisconsin, USA, Agric. Forest Meteorol., 126, 271-295, 2004.

Efron, B. and Tibshirani, R. J.: An Introduction to the Bootstrap, Chapman \& Hall, New York, 1993.

Falge, E., Baldocchi, D., Olson, R., Anthoni, P., Aubinet, M., Bernhofer, C., Burba, G., Ceulemans, R., Clement, R., Dolman, H., Granier, A., Gross, P., Grünwald, T., Hollinger, D., Jensen, N.O., Katul, G., Keronen, P., Kowalski, A., Lai, C. T., Law, B. E., Meyers, T., Moncrieff, J., Moors, E., Munger, J. W., Pilegaard, K., Rannik, Ü., Rebmann, C., Suyker, A., Tenhunen, J., Tu, K., Verma, S., Vesala, T., Wilson, K., and Wofsy, S.: Gap filling strategies for defensible annual sums of net ecosystem exchange, Agric. Forest Meteorol., 107, 43-69, 2001.

Feigenwinter, C., Bernhofer, C., and Vogt, R.: The Influence of Advection on the Short Term $\mathrm{CO}_{2}$ - Budget in and Above a Forest Canopy, Boundary-Layer Meteorol., 113, 201-224, 2004.

Feigenwinter, C., Heinesch, B., Yernaux, M., Bernhofer, C., Eichelmann, U., Moderow, U., Queck, R., Kolle, O., Hertel, M., Zeri, M., Ziegler, W., Lindroth, A., Mölder, M., Lagergren, F., Montagnani, L., Minerbi, S., Minach, L., Janous, D., Pavelka, M., Acosta, M., and Aubinet, M.: The CarboEurope-IP advection activities ADVEX'05: A joint effort to improve experimental and methodological approches of $\mathrm{CO}_{2}$ advection measurements, Geophys. Res. Abstracts, 8, 1607-7962/gra/EGU1606-A-03724, 2006.

Finnigan, J., Aubinet, M., Katul, G., Leuning, R., and Schimel, D.: Report of a Specialist Workshop on "Flux Measurements in Difficult Conditions", January 26-28, Boulder Colorado, Bull. Am. Meteorol. Soc., in press, 2006.

Göckede, M., Markkanen, T., Hasager, C. B. and Foken, T.: Update of a Footprint-Based Approach for the Characterisation of Complex Measurement Sites, Boundary-Layer Meteorology, 118, 635-655, 2006.

Goulden, M. L., Munger, J. W., Fan, S. M., Daube, B. C., and Wofsy, S.: Measurements of carbon sequestration by long-term eddy covariance: methods and a critical evaluation of accuracy, Global Change Biol., 2, 169-182, 1996.

Granier, A., Ceschia, E., Damesin, C., Dufrêne, E., Epron, D., Gross, P., Lebaube, S., Le Dantec, V., Le Goff, N., Lemoine, D., Lucot, E., Ottorini, J. M., Pontailler, J. Y., and Saugier, B.: The carbon balance of a young Beech forest, Functional Ecol., 14, 312-325, 2000.

Grunzweig, J. M., Lin, T., Rotenberg, E., Schwartz, A., and Yakir, D.: Carbon sequestration in arid-land forest, Global Change Biol., 9, 791-799, 2003.

Gu, L., Falge, E. M., Boden, T., Baldocchi, D. D., Black, T. A., Saleska, S. R., Suni, T., Verma, S. B., Vesala, T., Wofsy, S. C., and $\mathrm{Xu}, \mathrm{L}$.: Objective threshold determination for nighttime eddy flux filtering, Agric. Forest Meteorol., 128, 179-197, 2005.

Haszpra, L., Barcza, Z., Davis, K. J., and Tarczay, K.: Long-term tall tower carbon dioxide flux monitoring over an area of mixed vegetation, Agric. Forest Meteorol., 132, 58-77, 2005.

Hollinger, D. and Richardson, A. D.: Uncertainty in eddy covariance measurements and its application to physiological models, Tree Physiology, 25, 873-885, 2005.

Knohl, A., Schulze, E.-D., Kolle, O., and Buchmann, N.: Large carbon uptake by an unmanaged 250-year-old deciduous forest in Central Germany, Agric. Forest Meteorol., 118, 151-167, 2003.

Lee, X., Massman, W. J., and Law, B.: Handbook of Micrometeorology: A Guide for Surface Flux Measurement and Analysis, Kluwer, Dordrecht, 2004.

Marcolla, B., Cescatti, A., Montagnani, L., Manca, G., Kerschbaumer, G., and Minerbi, S.: Importance of advection in the atmospheric $\mathrm{CO}_{2}$ exchanges of an alpine forest, Agric. Forest Meteorol., 130, 193-206, 2005.

Massman, W. J. and Lee, X.: Eddy covariance flux corrections and uncertainties in long-term studies of carbon and energy exchanges, Agric. Forest Meteorol., 113, 121-144, 2002.

Moncrieff, J., Mahli, Y., and Leuning, R.: The propagation of errors in long-term measurements of land-atmosphere fluxes of carbon and water, Global Change Biol., 2, 231-240, 1996.

Papale, D. and Valentini, R.: A new assessment of European forests carbon exchanges by eddy fluxes and artificial neural network spatialization, Global Change Biol., 9, 525-535, 2003.

Papale, D. and Reichstein, M.: Centralized quality checks and gap filling used in the CarboeuropeIP Database, AmeriFlux annual meeting 2005, 18-20 October 2005, Boulder Colorado USA.

Rambal, S., Joffre, R., Ourcival, J. M., Cavender-Bares, J., and Rocheteau, A.: The growth respiration component in eddy $\mathrm{CO}_{2}$ flux from a Quercus ilex mediterranean forest, Global Change Biol., 
10, 1460-1469, 2004.

Rebmann, C., Göckede, M., Foken, T., Aubinet, M., Aurela, M., Berbigier, P., Bernhofer, C., Buchmann, N., Carrara, A., Cescatti, A., Ceulemans, R., Clement, R., Elbers, J. A., Granier, A., Grunwald, T., Guyon, D., Havrankova, K., Heinesch, B., Knohl, A., Laurila, T., Longdoz, B., Marcolla, B., Markkanen, T., Miglietta, F., Moncrieff, J., Montagnani, L., Moors, E., Nardino, M., Ourcival, J. M., Rambal, S., Rannik, Ü., Rotenberg, E., Sedlak, P., Unterhuber, G., Vesala, T., and Yakir, D.: Quality analysis applied on eddy covariance measurements at complex forest sites using footprint modelling, Theoretical and Applied Climatology, 80, 121-141, 2005.

Reichstein, M., Tenhunen, J., Roupsard, O., Ourcival, J.-M., Rambal, S., Miglietta, F., Peressotti, A., Pecchiari, M., Tirone, G., and Valentini, R.: Inverse modeling of seasonal drought effects on canopy $\mathrm{CO}_{2} / \mathrm{H}_{2} \mathrm{O}$ exchange in three Mediterranean ecosystems, J. Geophys. Res., 108, 2003.

Reichstein, M., Falge, E., Baldocchi, D., Papale, D., Aubinet, M., Berbigier, P., Bernhofer, C., Buchmann, N., Gilmanov, T., Granier, A., Grünwald, T., Havránková, K., Ilvesniemi, H., Janous, D., Knohl, A., Laurila, T., Lohila, A., Loustau, D., Matteucci, G., Meyers, T., Miglietta, F., Ourcival, J.-M., Pumpanen, J., Rambal, S., Rotenberg, E., Sanz, M., Tenhunen, J., Seufert, G., Vaccari, F., Vesala, T., Yakir, D., and Valentini, R.: On the separation of net ecosystem exchange into assimilation and ecosystem respiration: review and improved algorithm, Global Change Biol., 11, 1424-1439, 2005.
Richardson, A. D., Hollinger, D. Y., Burba, G. G., Davis, K. J., Flanagan, L. B., Katul, G. G., William Munger, J., Ricciuto, D. M., Stoy, P. C., Suyker, A. E., Verma, S. B., and Wofsy, S. C.: A multi-site analysis of random error in tower-based measurements of carbon and energy fluxes, Agric. Forest Meteorol., 136, 1-18, 2006.

Ruppert, J., Mauder, M., Thomas, C., and Lüers, J.: Innovative gapfilling strategy for annual sums of $\mathrm{CO}_{2}$ net ecosystem exchange, Agric. Forest Meteorol., 138, 5-18, 2006.

Sachs, L.: Angewandte Statistik: Anwendung Statistischer Methoden, Springer, Berlin, 1996.

Staebler, R. M. and Fitzjarrald, D. R.: Observing subcanopy $\mathrm{CO}_{2}$ advection, Agric. Forest Meteorol., 122, 139-156, 2004.

Suni, T., Rinne, J., Reissell, A., Altimir, N., Keronen, P., Rannik, Ü., Dal Maso, M., Kulmala, M. and Vesala, T.: Long-term measurements of surface fluxes above a Scots pine forest in Hyytiala, southern Finland, 1996-2001, Boreal Environ. Res., 8, 287-301, 2003.

Tedeschi, V., Rey, A. N. A., Manca, G., Valentini, R., Jarvis, P. G., and Borghetti, M.: Soil respiration in a Mediterranean oak forest at different developmental stages after coppicing, Global Change Biol., 12, 110-121, 2006.

Wohlfahrt, G., Anfang, C., Bahn, M., Haslwanter, A., Newesely, C., Schmitt, M., Drösler, M., Pfadenhauer, J., and Cernusca, A.: Quantifying nighttime ecosystem respiration of a meadow using eddy covariance, chambers and modelling, Agric. Forest Meteorol., 128, 141-162, 2005. 